\title{
FUNCTIONAL PLANT BIOLOGY
}

\section{publish.csiro.au/fp}
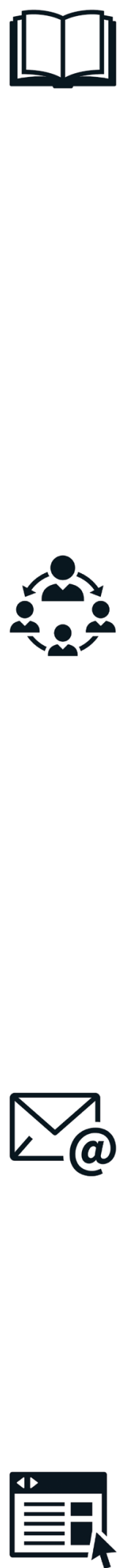

\section{SUBMIT YOUR ARTICLE ONLINE}

- Prepare: publish.csiro.au/fp/forauthors

- Submit: mc.manuscriptcentral.com/csiro-fp

- No page charges

- Rapid online publication ahead of issue release

- $\quad$ Eligible authors receive APC-free Open Access

\section{STAY IN CONTACT}

- publishing.fpb@csiro.au \#FunctionalPlantBio

- Sign up for free journals content emails publish.csiro.au/earlyalert

- Recommend the journal to your librarian publish.csiro.au/journals/recommend

\section{Functional Plant Biology}

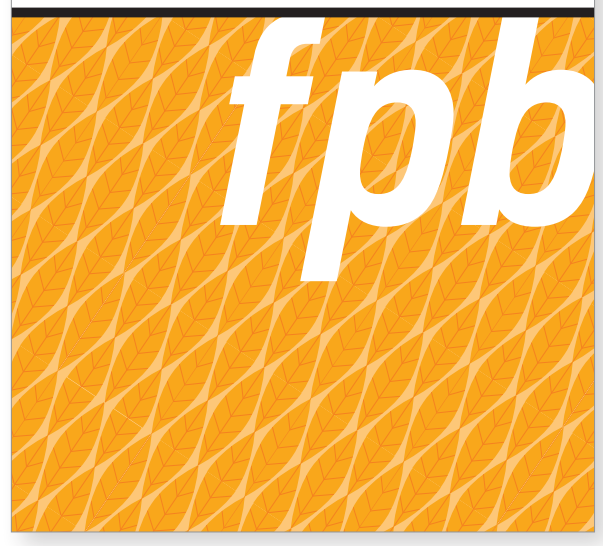

Editor-in-Chief:

Sergey Shabala

University of Tasmania

Publishing Model: Hybrid Open Access options available

Frequency: 12 issues/year

Publishing since: 1974

eISSN: 1445-4416 (online)

- Join the conversation on social media using hashtag

LEARN MORE ABOUT THE

JOURNAL

AUSTRALIAN SOCIETY OF PLANT SCIENTISTS

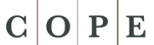

JM12795

As a member of the Committee on Publication Ethics (COPE), Functional Plant Biology supports its core practices and is committed to transparency in scholarly publishing.

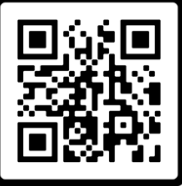

SCAN ME 


\section{JOURNAL METRICS}

\section{SPEED}

42 days from manuscript submission to first decision

$\mathbf{2 8}$ days from manuscript acceptance to publication

\section{USAGE}

187,058 downloads in 2021

239 Altmetrics mentions in 2021

\section{REJECTION RATE}

$\mathbf{7 1 \%}$ rejection rate in 2021

\section{IMPACT}

\# Ranking in area

90/238 in Plant Sciences (Q2)

2.8 Impact Factor

3.3 5-Year Impact Factor

TC $\mathbf{7 6 3 4}$ Total Citations in 2021

JcI 0.8 Journal Citation Indicator

cs $\mathbf{5 . 3}$ CiteScore

Highest percentile 84\% (59/370 Agronomy and Crop Science)

SNIP $1.0 \mathrm{SNIP}$

Source Normalised Impact per Paper

SJR $\quad 0.7 \mathrm{SJR}$

SCImago Journal Rank

h5 32 h5-index

Google Scholar index for papers published 2017-21

\section{ABOUT CSIRO PUBLISHING}

CSIRO Publishing operates as an editorially independent science publisher within Australia's premier research group, Commonwealth Scientific and Industrial Research Organisation (CSIRO), and has been publishing journals since 1948. Our internationally recognised publishing program includes journals, books and magazines and covers a wide range of scientific disciplines.

\section{PARTNER ORGANISATIONS}

The Association of Society Publishers

Copyright Clearance Center

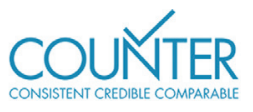

research4 life
Crossref

Altmetric

$\$$ Dimensions

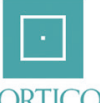

\section{publons}

